DOI: $10.5216 /$ cab.v14i4.14028

\title{
CARACTERÍSTICAS FÍSICO-QUÍMICAS E CELULARIDADE DO LEITE DE OVELHAS SANTA INÊS EM DIFERENTES ESTÁGIOS DE LACTAÇÃO
}

\author{
Maiara G Blagitz ${ }^{1}$, Camila Freitas Batista ${ }^{2}$, Viviani Gomes ${ }^{3}$, Fernando Nogueira DE \\ SOUZA $^{4}$, Alice MARIA MELVILle PAIVA DELla LiBERA $^{3}$ \\ ${ }^{1}$ Professora Doutora da Universidade Federal do Paraná, Palotina, PR, Brasil. \\ ${ }^{2}$ Pós-Graduanda da Faculdade de Medicina Veterinária e Zootecnia da Universidade de São Paulo, São Paulo, SP, \\ Brasil \\ ${ }^{3}$ Professoras Doutoras da Faculdade de Medicina Veterinária e Zootecnia da Universidade de São Paulo, São \\ Paulo, SP, Brasil \\ ${ }^{4}$ Pós-Graduando da Universidade Federal de Minas Gerais, Belo Horizonte, MG, Brasil. nogueirasouza@yahoo.com.br
}

\section{RESUMO}

O presente trabalho teve como objetivo investigar a influência do estágio da lactação sobre as características físico-químicas e a celularidade do leite em ovelhas da raça Santa Inês. Desse modo, 143 amostras de leite negativas no exame bacteriológico e sem alterações na prova da caneca de fundo escuro provenientes de 33 ovelhas Santa Inês foram utilizadas para determinar a contagem automática e microscópica de células somáticas, os teores de extrato seco total, gordura, lactose e proteína. Os resultados do presente estudo apontaram para aumento da celularidade do leite e dos teores de gordura e proteína e redução do teor de lactose no final da lactação, embora não tenham sido observadas alterações no extrato seco total no leite desses animais durante a lactação. O presente estudo apontou ainda para correlação significativa entre a contagem automática e a microscópica de células somáticas $(r=0,80)$, a porcentagem de leucócitos mononucleares $(r=-0,45)$, a porcentagem de leucócitos polimorfonucleares $(\mathrm{r}=0,45)$, os teores de lactose $(\mathrm{r}=$ $0,44)$, proteína $(r=0,37)$ e gordura $(r=0,30)$. No entanto, não se observou correlação significativa entre a CCS automática e o teor de extrato seco total $(r=0,007)$.

PALAVRAS-CHAVE: Contagem de células somáticas; glândula mamária; pequenos ruminantes; qualidade do leite.

\section{EFFECT OF LACTATION STAGE ON MILK PHYSICO-CHEMICAL CHARACTERISTICS AND SOMATIC CELL COUNT FROM SANTA INES EWES}

\section{ABSTRACT}

The purpose of the present trial was to investigate the influence of lactation stage on milk cellularity and physicochemical characteristics. Thus, 143 milk samples from 33 Santa Ines ewes negative in the bacteriological examination and without any alteration in the strip cup test were used to determine the automatic and microscopic somatic cell count (SCC), and the fat, lactose, protein and total solids content. The results of the present study showed an augment in the SCC and in the fat and protein content, besides a reduction in lactose content at the last lactation stage. Otherwise, no alteration was observed in the total solids content during the lactation period. This study pointed out to a significant correlation between the automatic SCC and the microscopic SCC ( $\mathrm{r}=0.80)$, percentage of polymorphonuclear leukocytes $(r=0.45)$, percentage of mononuclear leukocytes $(\mathrm{r}=-0.45)$, lactose $(r=-0.44)$, protein $(r=0.37)$ and fat $(r=0.30)$ content. Nevertheless, significant correlation between the automatic SCC and the total solids content was not observed.

KEYWORDS: Mammary gland; milk quality; small ruminants; somatic cell count. 


\section{INTRODUÇÃO}

A ovinocultura brasileira está em ascensão, contando com um rebanho de mais de 17 milhões de animais (RESENDE et al., 2010). O leite de ovelhas difere do das demais espécies especialmente pela riqueza dos constituintes, e sua composição ser influenciada pelo ambiente, raça, idade da ovelha, estágio de lactação, manejo de ordenha, estado sanitário e nutrição (QUEIROZ et al., 2009). No entanto, em pequenos ruminantes, um dos fatores fisiológicos que mais contribuem para as alterações na composição do leite é o estágio da lactação (ALBENZIO et al., 2004; SEVI et al., 2004).

As enfermidades das glândulas mamárias de ovinos e caprinos são pouco conhecidas quando comparadas com as dos bovinos. Essa ausência de informações na literatura não significa que sejam menos importantes, mas, sim, que essas espécies ainda são pouco estudadas. Para os animais leiteiros, a mastite acarreta perdas na produtividade e na produção de seus derivados. Para os animais destinados ao corte, a mastite ocasiona baixa produção de leite da mãe e, consequentemente, baixo ganho de peso dos cordeiros. Deste modo, a importância da mastite na ovinocultura está relacionada com aspectos econômicos e higiênicos (BERGONIER et al., 2003).

O leite ovino é raramente consumido in natura, ele apresenta excelente rendimento para a fabricação de queijos, devido ao alto teor de gordura em sua composição. O iogurte é mais leve e mais nutritivo que o produzido a partir do leite de vaca e também é indicado como alimento especial para crianças com intolerância ao leite bovino (DE OLIVEIRA, 2006). Nesse contexto, os fatores que influenciam a qualidade do leite de ovinos têm recebido grande atenção nos últimos anos.

Um dos meios muito utilizados para o diagnóstico de mastite bovina é a contagem de células somáticas (CCS). Contudo, nos pequenos ruminantes, apesar da eficiência da CCS na identificação de processos inflamatórios, diante de alguns fatores, seus resultados tornam-se vulneráveis. A CCS pode ser influenciada por fatores fisiológicos, como estresse, fase da lactação, idade da fêmea (BOSCOS et al., 1996;
CONTRERAS et al., 1996; LAFI et al., 1998; SEVI, et al., 2000; PAAPE et al., 2001; ALBENZIO et al., 2003; LEITNER et al., 2003; BERGONIER et al., 2003; BIANCHI et al., 2004; GONZALO et al., 2004; ANDERSON et al., 2005), número de lactações, frações do leite, raças, estados nutricionais (GONZÁLEZ-RODRÍGUEZ et al., 1995; PAAPE et al., 2001; BERGONIER et al., 2003; FTHENAKIS et al., 2004; ANDERSON et al., 2005) e por fatores patológicos como a infecção intra-mamária (CONTREAS et al., 1996; KIRK et al., 1996; BURRIEL, 2000; PAAPE et al., 2001; BERGONIER et al., 2003). A influência de fatores fisiológicos na CCS é menos significante do que a de fatores patológicos (CUCCURU et al., 1997).

A CCS pode ser avaliada pela contagem automática e pela contagem microscópica. Para a CCS automática, é necessário que as amostras de leite sejam enviadas em frascos próprios e imersas em conservantes ideais para laboratórios especializados e credenciados pelo Ministério da Agricultura e Abastecimento. Para a CCS microscópica, é necessário apenas o conhecimento de colorações mais adequadas para a secreção láctea da espécie a ser avaliada (PENGOV, 2001). Alterações na composição láctea também são indicativas de mastite (AULDIST et al., 1995). A amplitude dessas alterações está subordinada à patogenicidade do agente etiológico envolvido e à área tecidual afetada (PYÖRALLÄ, 2003). As principais alterações na mama incluem a passagem de íons, proteínas e enzimas do sangue para o leite devido ao aumento da permeabilidade, invasão de fagócitos e redução da capacidade de síntese láctea da glândula (MCDOUGALL et al., 2001; McCARTHY et al., 2009). Alguns componentes são mais marcantes que outros, podendo ser utilizados como ferramenta para a detecção do processo inflamatório (PYÖRALLÄ, 2003).

Porém, apesar do vasto conhecimento sobre ruminantes, particularmente bovinos, grande parte das informações disponíveis para ovinos encontra-se nos países mediterrâneos, sendo, em sua maioria, sobre raças especializadas para a produção de leite. Desse modo, essas informações são pouco disponíveis para ovinos não especializados para a produção de leite e criados em sistemas extensivos e semi-extensivos como os da raça Santa Inês, que apresenta expressivo 
aumento populacional no país. Ovinos da raça Bergamácia, de potencial leiteiro, participaram da formação da raça Santa Inês, proporcionando produção de leite similar às raças especializadas como a Lacaune, Awassi e East Friesian (RIBEIRO et al., 2007).

Dessa forma, o objetivo do presente trabalho foi investigar a influência do estágio da lactação sobre as características físico-químicas e da celularidade do leite em ovelhas da raça Santa Inês.

\section{MATERIAL E MÉTODOS}

No presente estudo, objetivando-se avaliar a influência da fase da lactação sobre as características físico-químicas e a celularidade do leite, foram incluídas apenas as amostras negativas no exame bacteriológico e sem alterações na prova de fundo escuro. Dessa forma, foram avaliadas 143 amostras de leite proveniente de 33 ovelhas da raça Santa Inês, divididas de acordo com a fase da lactação, a saber: amostras entre o terceiro e o $30^{\circ}$ dia após o parto (fase 1$)(\mathrm{n}=49)$, entre o $31^{\circ}$ e o $60^{\circ}$ após o parto (fase 2$)(\mathrm{n}=47)$, entre o $61^{\circ}$ e o $90^{\circ}$ dia após o parto (fase 3$)(\mathrm{n}=32)$, e acima de 90 dias de lactação (fase 4) $(\mathrm{n}=15)$. Alguns animais morreram ou foram vendidos pelos proprietários.

As amostras de leite, após o descarte dos primeiros jatos e a devida assepsia, foram coletadas e destinadas para o exame bacteriológico conforme as recomendações do National Mastistis Council (HARMON et al., 1990), determinação dos teores de gordura, lactose, proteína e extrato seco total e contagem microscópica e automática de células somáticas.

As amostras de leite destinadas ao exame bacteriológico foram semeadas em placas de Petri contendo ágar-sangue de carneiro (5\%) e incubadas a $37^{\circ} \mathrm{C}$ por 72 horas, e a leitura foi realizada a cada 24 horas, como recomendado por OLIVER et al. (2004). Essas amostras de leite foram também encaminhadas ao Laboratório de Qualidade de Leite credenciado ao Ministério da Agricultura, Pecuária e Abastecimento da Escola Superior de Agricultura "Luiz de Queiroz" para a determinação dos teores de gordura, lactose, proteína e extrato seco total.

As amostras de leite destinadas à contagem automática de células somáticas foram acondicionadas em frasco plástico contendo $8 \mathrm{mg}$ de Bronopol (2-bromo-2-nitropropano-1-3, diol) e
0,3 mg do antifúngico natamicina. A CCS automática foi realizada por contador automático de células somáticas pelo método fossomático no Laboratório de Qualidade de Leite credenciado ao Ministério da Agricultura, Pecuária e Abastecimento da Escola Superior de Agricultura "Luiz de Queiroz".

Para determinação da contagem microscópica direta de células somáticas, $10 \mu \mathrm{L}$ de leite foram distribuídos em $1 \mathrm{~cm}^{2}$. A coloração foi realizada utilizando-se o corante BroadhurstPalley (BP) (azul de metileno e fucsina) e, posteriormente, as lâminas foram fixadas por 10 minutos como descrito por PAAPE et al. (2001). Efetuou-se a contagem leucocitária em cem campos visuais das lâminas confeccionadas usando-se objetiva de imersão e multiplicou-se esse valor pelo fator microscópico previamente calculado (PAAPE et al., 2001). Foram diferenciados os leucócitos mononucleares dos polimorfonucleares.

A distribuição de Gaussian foi verificada pelo teste de Kolmogorov e Smirnov. Posteriormente, os dados com distribuição paramétrica foram submetidos à análise de variância (ANOVA) para verificação das diferenças entre os grupos. Quando houve diferença significativa, procedeu-se o teste de Tukey-Kramer para comparações múltiplas entre as médias. Para os dados com distribuição não paramétrica, o teste de Kruskall-Wallis foi utilizado. A correlação de Spearman foi aplicada para determinação da correlação entre a contagem automática de células somáticas e a contagem microscópica de células somáticas, a porcentagem de leucócitos polimorfonucleares e mononucleares e os teores de lactose e proteína. A correlação de Pearson foi utilizada para verificação da correlação entre a contagem automática de células somáticas e os teores de gordura e extrato seco total. A análise estatística foi realizada utilizandose o programa GraphPad Prisma 5.0 software (GraphPad Software, Inc., San Diego, CA, USA).

\section{RESULTADOS}

Os resultados do presente estudo apontaram para maior teor de gordura $(P=0,0035)$ na última fase da lactação comparada às outras fases. Observou-se também maior teor de proteína $(P=0,0065)$ e menor teor de lactose $(P=0,0066)$ na última fase da lactação em relação à primeira e segunda fases. No entanto, não foram observadas 
alterações no conteúdo de extrato seco total durante a lactação $(P=0,62)$ (Tabela 1$)$.

$\mathrm{O}$ presente estudo demonstrou maior contagem automática de células somáticas na última fase da lactação (155.000 - 12.582.000 células $/ \mathrm{mL})$ em comparação à primeira $(8.000$ 6.144 .000 células $/ \mathrm{mL}$ ) e à segunda fases da lactação $\quad(12.000-7.359 .000 \quad$ células $/ \mathrm{mL})$ $(P=0,03)$. Do mesmo modo, observou-se maior contagem microscópica de células somáticas após 90 dias de lactação $(558.378$ - 6.080 .000 células $/ \mathrm{mL})$ em relação à primeira $(10.723$ 5.917.000 células $/ \mathrm{mL}$ ) e à segunda (46.423 3.464 .000 células $/ \mathrm{mL}$ ) fases da lactação $(P=0,004)$. Por outro lado, não foram observadas diferenças na porcentagem de leucócitos polimorfonucleares e mononucleares $(P=0,79)$ nas distintas fases da lactação.

O presente estudo apontou uma correlação significativa entre a contagem automática e microscópica de células somáticas $(\mathrm{r}=0,80$, $P<0,0001)$ a porcentagem de leucócitos mononucleares $(\mathrm{r}=-0,45 ; \quad P<0,0001), \quad \mathrm{a}$ porcentagem de leucócitos polimorfonucleares $(\mathrm{r}=$ $0,45 ; P<0,0001)$ e os teores de lactose $(\mathrm{r}=-0,44$; $P<0,0001)$, proteína $(\mathrm{r}=0,37 ; P<0,0001)$ e gordura $(\mathrm{r}=0,30 ; P=0,0003)$. No entanto, não se observou correlação significativa entre a CCS automática e o teor de extrato seco total $(\mathrm{r}=0,007$; $P=0,93$ ).

Observou-se também correlação significativa entre os dias em lactação e a contagem automática de células somáticas $(\mathrm{r}=$ $0,18, P=0,03)$ e a contagem microscópica de células somáticas $(\mathrm{r}=0,20 ; \quad P=0,018)$, a porcentagem de leucócitos mononucleares $(\mathrm{r}=$ $0,06 ; \quad P=0,50)$, a porcentagem de leucócitos polimorfonucleares $(\mathrm{r}=0,06 ; P=0,50)$, os teores de lactose $(\mathrm{r}=-0,29 ; P=0,0004)$, proteína $(\mathrm{r}=$ $0,25 ; P=0,0026)$ e gordura $(\mathrm{r}=0,23 ; P=0,0047)$. No entanto, não se observou correlação significativa entre os dias em lactação e o teor de extrato seco total $(r=-0,006 ; P=0,45)$.

Tabela 1. Características físico-químicas do leite de ovelhas da raça Santa Inês nas diferentes fases da lactação

\begin{tabular}{lcccc}
\hline Dias em Lactação & $\begin{array}{c}\text { Gordura } \\
(\mathrm{g} / \mathrm{dL})\end{array}$ & $\begin{array}{c}\text { Lactose } \\
(\mathrm{g} / \mathrm{dL})\end{array}$ & $\begin{array}{c}\text { Proteína } \\
(\mathrm{g} / \mathrm{dL})\end{array}$ & $\begin{array}{c}\text { Extrato seco total } \\
(\mathrm{g} / \mathrm{dL})\end{array}$ \\
\hline 3 a 30 & $6,75( \pm 3,38)^{\mathrm{a}}$ & $4,51( \pm 1,47)^{\mathrm{a}}$ & $5,41( \pm 1,73)^{\mathrm{a}}$ & $16,58( \pm 4,21)^{\mathrm{a}}$ \\
31 a 60 & $6,91( \pm 1,73)^{\mathrm{a}}$ & $4,41( \pm 0,70)^{\mathrm{a}}$ & $5,28( \pm 0,81)^{\mathrm{a}}$ & $16,33( \pm 2,23)^{\mathrm{a}}$ \\
61 a 90 & $7,31( \pm 2,38)^{\mathrm{a}}$ & $4,11( \pm 0,99)^{\mathrm{ab}}$ & $5,71( \pm 1,25)^{\mathrm{ab}}$ & $15,77( \pm 2,75)^{\mathrm{a}}$ \\
Acima de 90 & $9,74( \pm 2,39)^{\mathrm{b}}$ & $3,47( \pm 0,86)^{\mathrm{b}}$ & $6,57( \pm 1,45)^{\mathrm{b}}$ & $16,93( \pm 2,21)^{\mathrm{a}}$ \\
\hline
\end{tabular}

Letras diferentes entre linhas indicam $P<0,05$.

Valores médios ( \pm desvio-padrão).

\section{DISCUSSÃO}

A influência da fase da lactação sobre as características físico-químicas e a celularidade do leite tem sido alvo de vários estudos em pequenos ruminantes. Quando comparadas as amostras de leite de ovelhas com as amostras de leite de vacas, podese dizer que as amostras de leite de ovelhas apresentam maior percentagem de gordura, de proteína e menor percentagem de lactose do que as amostras de leite de vacas (JANDAL, 1996). Em pesquisa com ovelhas da raça Santa Inês criadas em sistema semi-intensivo no Sergipe, OLIVEIRA (2006) observou aumento do teor de gordura e proteína e redução da lactose com o decorrer da lactação, como encontrado no presente estudo. Similarmente, SNOWDER \& GLIMP (1991) também relataram queda no teor de lactose a partir do $28^{\circ}$ dia de lactação.

Já McCARTHY et al. (2009) observaram diferenças na composição láctea relacionadas com as espécies. Esses autores compararam raças Landrace, Dorset, Rambouillet, Landrace com Dorset e Barbados Blackybelly com Dorset e observaram que as amostras de leite das ovelhas Landrace apresentaram maior quantidade de proteína e menor percentagem de gordura do que as amostras de leite das ovelhas de outras raças. As ovelhas Landrace e Dorset apresentaram maiores quantidades de lactose e de gordura do que as ovelhas de outras raças.

Os dados do presente estudo também corroboram com os achados de BIANCHI et al. (2004), ALBENZIO et al. (2004) e ALBENZIO et al. (2005), que relataram decréscimo do teor de lactose e aumento dos teores de proteína e gordura com o decorrer da lactação. Do mesmo modo, 
BRITO et al. (2006) observaram aumento progressivo do teor de proteína e gordura com o avanço da lactação em ovelhas da raça Lacaune, sendo que o maior teor de lactose coincidiu com o pico da lactação (30 dias de lactação). Considerandose a celularidade do leite, observou-se aumento da CCS no final da lactação, corroborando os achados de GONZALO et al. (1994) e BRITO et al. (2006), o que sugere que o aumento da celularidade no final da lactação está relacionado com a maior resistência a infecções intramamárias neste período (BLAGITZ et al., 2008; BLAGITZ et al., 2012; SOUZA et al., 2012). O aumento no teor de gordura e proteína e na CCS pode ser explicado, pelo menos em parte, pelo fator de diluição, demonstrado pelo padrão inverso entre o volume de leite produzido ao longo da lactação e o teor desses constituintes do leite, em contraste com a redução do teor de lactose que regula a produção de leite (FERREIRA et al., 2011).

CUNHA et al. (2008), trabalhando com vacas holandesas, observaram que quanto maior a quantidade de lactações e a celularidade, menor é a percentagem de proteína e quanto menor a quantidade de lactação e de celularidade, maior é a percentagem de gordura.

Os teores de lactose encontrados no presente estudo até os 90 dias de lactação são similares aos encontrados por SNOWDER \& GLIMP (1991) e SEVI et al. (2004), porém são inferiores aos descritos por BRITO et al. (2006). Em relação ao extrato seco total, os valores encontrados neste estudo foram similares aos descritos por BRITO et al. (2006) e RIBEIRO et al. (2007), que encontraram valores médios de $16,25 \%$ e $16,18 \%$, respectivamente; no entanto, os valores de proteína e gordura foram superiores aos descritos por BRITO et al. (2006) e RIBEIRO et al. (2007). Essas diferenças provavelmente devem-se à menor produção de leite dos animais utilizados no presente estudo considerando a raça e o sistema de criação, em relação, por exemplo, à raça Lacaune utilizada por BRITO et al. (2006) criadas em sistema intensivo, já que há uma correlação negativa entre a produção de leite e as características físico-químicas do leite (DE SÁ et al., 2005; FERREIRA et al., 2011). No entanto, os resultados encontrados no presente estudo são similares aos descritos por GONZALO et al. (1994) e BIANCHI et al. (2004).

Os valores da CCS observados no presente trabalho foram superiores aos descritos por DE SÁ et al. (2005), para ovelhas da raça Bergamácia, e BRITO et al. (2006), para ovinos da raça Lacaune, e inferiores aos valores encontradas por FTHENAKIS et al. (1996), para ovelhas das raças WelshMountain, Dorset-Horn e Chios. Salienta-se que, embora as amostras positivas no exame bacteriológico tenham sido excluídas do presente estudo, a alta celularidade encontrada em algumas amostras (ex. CCS $\geq 1 \times 10^{6}$ células $/ \mathrm{mL}$ ) aponta para a possibilidade de inclusão de amostras provenientes de mamas infectadas, principalmente ao se considerar os valores de corte propostos para identificação de processos inflamatórios e/ou infecciosos da glândula mamária em ovelhas da raça Santa Inês $\left(5 \times 10^{5}\right.$ células $\left./ \mathrm{mL}\right)$ (NUNES et al., 2008; SOUZA et al., 2012), apesar de a fase da lactação não infuenciar a ocorrência de novas infecções intramamárias (BLAGITZ et al., 2012).

Inúmeros estudos têm demonstrado que o aumento na CCS está associado com mudanças na composição do leite, que estão relacionadas com a redução da síntese de constituintes do leite (ex. lactose) (RAYNAL-LJUTOVAC et al., 2007), como encontrado no presente estudo. Dessa forma, é amplamente aceito que o aumento da celularidade do leite está associado à redução na concentração de lactose (RAYNAL-LJUTOVAC et al., 2007). Entretanto, o conteúdo de extrato seco total pode se apresentar sem alterações, como encontrado no presente estudo (RAYNAL-LJUTOVAC et al., 2007) ou menor (JAEGGI et al., 2003) com o aumento da celularidade. Tal fato deve-se provavelmente ao aumento da concentração de minerais como o sódio e o cloro (RAYNALLJUTOVAC et al., 2007) na tentativa de manter a osmolaridade do leite devido à redução no conteúdo de lactose.

A concentração total de proteínas apresenta resultados discordantes, sendo algumas vezes descrito aumento, como encontrado no presente estudo (BIANCHI et al., 2004), redução ou até mesmo nenhuma alteração (RAYNAL-LJUTOVAC et al., 2007) com o aumento da celularidade do leite. Neste contexto, RAYNAL-LJUTOVAC et al. (2007) relataram redução da porcentagem de $\beta$ lactoglobulina, enquanto que as concentrações de albumina sérica e imunoglobulinas aumentaram. Assim, é esperado que o aumento de proteínas séricas (ALBENZIO et al., 2004) possa levar ao aumento da concentração de proteínas verdadeiras e a menor concentração de caseína é decorrente da menor síntese, expressa como porcentagem da proteína verdadeira (RAYNAL-LJUTOVAC et al., 2007).

No presente trabalho, diferentemente do relatado por DE OLIVEIRA (2006), observou-se aumento do teor de gordura com o aumento da celularidade do leite. Isso, provavelmente, está associado à menor produção de leite com o avanço da lactação, o que acarretaria maior celularidade e maior teor de gordura do leite. Enfatiza-se que, embora a redução de síntese de gordura pareça lógica 
devido ao aumento da celularidade, no caso, como foram excluídas as amostras positivas no exame bacteriológico, o efeito do aumento da celularidade decorrente da mastite tornou-se imperceptível. Dessa forma, acredita-se que as correlações entre a celularidade do leite e as características físicoquímicas do leite encontradas no presente estudo devem-se principalmente a alterações da produção de leite com o avanço da lactação.

Dentre os métodos de contagem automática de células somáticas, a CCS baseada em citometria de fluxo, utilizada no presente estudo, tem apresentado resultados interessantes. Isso se deve à utilização do brometo de etídio que se liga ao ácido desoxiribonucléico no núcleo celular (GONZALO et al., 2004). Esse método quantifica as células epiteliais e os leucócitos, não enumerando os corpúsculos citoplasmáticos. Ademais, a rapidez, a repetibilidade e o custo viabilizam o uso dessa metodologia (GONZALO et al., 2003; GONZALO et al., 2004). Assim, altas correlações entre a CCS microscópica e a CCS automática, baseada na citometria de fluxo, têm sido reportadas para a espécie ovina (GONZALO et al., 2003), apesar de serem descritas variações metodológicas na contagem de células somáticas do leite de ovelhas devido à presença de corpúsculos citoplasmáticos no leite dessa espécie (BLAGITZ et al., 2013).

Além disso, outro fato que deve ser considerado no presente trabalho é a duração da lactação. Observou-se que a duração da lactação nas ovelhas da raça Santa Inês criadas em sistemas semiintensivos e extensivos foi inferior à das raças especializadas, considerado-se os dados de estudos anteriores (BRITO et al., 2006; CASTILLO et al., 2009), que relataram períodos superiores a 120 dias de lactação. No presente estudo, grande parte dos cordeiros foram desmamados naturalmente por volta dos 45 dias de idade, embora algumas ovelhas tenham amamentado até os 120 dias de lactação.

\section{CONCLUSÃO}

A fase da lactação foi responsável por alterações no teor de gordura, lactose e proteína e na celularidade do leite, embora não tenha sido observada alteração no teor de extrato seco total no leite de ovelhas da raça Santa Inês no final da lactação. O presente estudo apontou ainda para aumento dos teores de proteína e gordura no leite e redução do teor de lactose com o aumento da contagem da celularidade nas metades mamárias de ovelhas da raça Santa Inês negativas no exame microbiológico e sem alterações na prova de fundo escuro; no entanto, alterações no teor de extrato seco total não foram associadas a celularidade do leite.

\section{AGRADECIMENTOS}

Parte integrante do Projeto $\mathrm{n}^{\circ}$ 03/08582-7 financiado pela Fundação de Amparo a Pesquisa do Estado de São Paulo.

\section{REFERÊNCIAS}

ALBENZIO, M.; CAROPRESE, M.; SANTILLO, A.; MARINO, R.; MUSCIO, A.; SEVI, A. Proteolytic patterns and plasmin activity in ewe's milk as affect by somatic cell count and stage of lactation. Journal of Dairy Research, v.72, p.86-92, 2005.

ALBENZIO, M.; CAROPRESE, M.; SANTILLO, A.; MARINO, R.; TAIBI, L.; SEVI, A. Effects of somatic cell count and stage of lactation on the plasmin activity and cheese-making properties of ewe milk. Journal of Dairy Science, v.87, p.533-542, 2004.

ALBENZIO, M.; TAIBI, L.; CAROPRESE, M.; DE ROSA, G.; MUSCIO, A.; SEVI, A. Immune response, udder health and productive traits of machine milked and suckling ewes. Small Ruminant Research, v.48, p.189200, 2003.

ANDERSON, D. E.; HULL, B. L.; PUGH, D. G. Enfermidades da glândula mamária. In: PUGH, D. G. Clínica de ovinos e caprinos. Editora Roca: São Paulo, 2005. $513 \mathrm{p}$.

AULDIST, M. J.; COATS, S.; ROGERS, G. L.; MCDOWELL, G. H. Changes in the composition of milk from healthy and mastitic dairy cows during the lactation cycle. Australian Journal of Experimental Agriculture, v.35, p.427-436, 1995.

BERGONIER, D.; BERTHELOT, X. New advances in epizootiology and control of ewe mastitis. Livestock Production Science, v.79, p.1-16, 2003.

BERTHELOT, X; LAGRIFFOUL, G.; CONCORDET, D.; BARILLET, F.; BERGONIER, D. Physiological and pathological thresholds of somatic cell counts in ewe milk. Small Ruminant Research, v.62, p.27-31, 2006.

BIANCHI, L.; BOLLA, A.; BUDELLI, E.; CAROLL, A.; CASOLI, C.; PAUSELLI, M.; DURANTI, E. Effect of udder health status and lactation phase on the characteristics of Sardinian ewe milk. Journal of Dairy Science, v.87, p.2401-2408, 2004.

BLAGITZ, M.G.; BATISTA, C.F.; SOUZA, F.N.; BENITES, N.R.; MELVILLE, P.A.; STRICAGNOLO, C.R.; RICCIARDI, M.; GOMES, V.; AZEDO, M.R.; SANCHES, B.G.S.; DELLA LIBERA, A.M.M.P. Perfil celular e microbiológico do leite de ovelhas Santa Inês no período lactante e pós-desmame. Pesquisa Veterinária Brasileira, v.28, p.417-422, 2008.

BLAGITZ, M.G.; BENITES, N.R.; BATISTA, C.F.; SOUZA, F.N.; DIAS, R.A.; GOMES, V.; DELLA LIBERA, A.M.M.P. Variações metodológicas na 
contagem de células somáticas do leite de ovelhas da raça Santa Inês. Ciência Rural, v.43, p.668-671, 2013.

BLAGITZ, M.G.; BENITES, N.R.; MELVILLE, P.A.; BATISTA, C.F.; BETIOL, P.S.; AZEDO, M.R.; GOMES, V.; SOUZA, F.N.; DELLA LIBERA, A.M.M.P. Lactation stage and udder health status of Santa Ines ewes. Arquivo Brasileiro de Medicina Veterinária e Zootecnia, v.64, p.495-498, 2012.

BOSCOS, C.; STEFANAKIS, A.; ALEXOPOULOS, C.; SAMARTZI, F. Prevalence of subclinical mastitis and influence of breed, parity, stage of lactation and mammary bacteriological status on coulter counter and california mastitis test in the milk of Saanen and autichthonous Greek goats. Small Ruminant Research, v.21, p.139$147,1996$.

BRITO, M.A.; GONZALEZ, F.D.; RIBEIRO, L.A.; CAMPOS, R.; LACERDA, L.; BARBOSA, P.R.; BERGMANN, G. Composição do sangue e do leite em ovinos leiteiros do sul do Brasil: variações na gestação e na lactação. Ciência Rural, v.36, n.3, p.942-948, 2006.

BURRIEL, A. R. Somatic cell counts determined by coulter or fossomatic counter and their relationship to administration of oxytocin. Small Ruminant Research, v.35, p.81-84, 2000.

CASTILlO, V.; SUCH, X.; CAJA, G.; CASALS, R.; SALAMA, A.A.K.; ALBANELL, E. Long and short term effects of omitting two weekend milkings on the lactational performance and mammary tight junctions permeability of dairy ewes. Journal of Dairy Science, v.92, p.3684-3695, 2009.

CONINGTON, J.; CAO, G.; STOTT, A.; BÜNGER, L. Breeding for resistance to mastitis in United Kingdom sheep, a review and economic appraisal. Veterinary Record, v.162, p.369-376, 2008.

CONTRERAS, A.; SIERRA, D.; CORRALES, J. C.; SANCHEZ, A.; MARCO, J. Physiological threshold of somatic cell count and california mastitis test for diagnosis of caprine subclinical mastitis. Small Ruminant Research, v.21, p.259-264, 1996.

CUCCURU, C.; MORONI, P.; ZECCONI, A.; CASU, S.; CARIA, A.; CONTINI, A. Milk differencial cell counts in relation to total counts in Sardinian ewes. Small Ruminant Research, v.25, p.169-173, 1997.

CUNHA, R.P.L.; MOLINA, L.R.; CARVALHO, A.U.; FACURY FILHO, E.J.; FERREIRA, P.M.; GENTILINI, M.B. Mastite subclínica e relação da contagem de células somáticas com número de lactações, produção e composição química do leite em vacas da raça Holandesa. Arquivo Brasileiro de Medicina Veterinária e Zootecnia, v.60, n.1, p.19-24, 2008.

DE OLIVEIRA, V.L.M. Aspectos do leite e mastite em ovinos da raça Santa Inês em Sergipe. Dissertação (Mestrado em Agrossistemas) - Núcleo de Pesquisa e Pós-Graduação e Estudos em Recursos Naturais, Universidade Federal de Sergipe. 2006. 71 p. Disponível em http://www.dominiopublico.gov.br/download/texto/c p010533.pdf acesso em novembro 2013.

DE SÁ, C.O.; SIQUEIRA, E.R.; DE SÁ, J.L.; FERNANDES, S. Influência do fotoperíodo no consumo alimentar, produção e composição do leite de ovelhas Bergamásia. Pesquisa Agropecuária Brasileira, v.40, n.6, p.601-608, 2005.

RESENDE, K. T.; TEIXEIRA, I. A. M. A.; BIAGIOLI, B.; LIMA, L. D.; BOAVENTURA NETO, O.; PEREIRA JUNIOR, J. D. Progresso científico em pequenos ruminantes na primeira década do século XXI. Revista Brasileira de Zootecnia, v. 39, p. 369-375, 2010.

FERREIRA, M.I.C.; BORGES, I.; MACEDO JUNIOR, G.L.; RODRIGUEZ, N.M.; PENNA, C.F.; SOUZA, M.R.; GOMES, M.G.T.; SOUZA, F.A.; CAVALCANTI, L.F. Produção e composição do leite de ovelhas Santa Inês e mestiças Lacaune e Santa Inês e desenvolvimento de seus cordeiros. Arquivo Brasileiro de Medicina Veterinária e Zootecnia, v.63, p.530-533, 2011.

FTHENAKIS, G.C.; LEONTIDES, L.; SKOUFOS, J.; TAITZOGLOU, I.A.; TZORA, A. Case report: high prevalence rate of ovine mastitis, caused by coagulasenegative staphylococci and predisposed by increased gossypol consumption. Small Ruminant Research, v.52, p.185-189, 2004.

FTHENAKIS, G.C. Somatic cell counts in milk of WelshMountain, Dorset-Horn and Chios ewes throughout lactation. Small Ruminant Research, v. 20, p. 155-162, 1996.

GONZÁLEZ-RODRÍGUEZ, M.C.; GONZALO, C.; SAN PRIMITIVO, F.; CÁRMENES, P. Relationship between somatic cell count and intramammary infection of the half udder in dairy ewe. Journal of Dairy Science, v.78, p.2753-2759, 1995.

GONZALO, C.; BARO, J.A.; CARRIEDO, J.A.; SAN PRIMITIVO, F. Use of fossomatic method to determine somatic cell counts in sheep. Journal of Dairy Science, v. 76, p. 115-119, 1993.

GONZALO, C.; BOIXO, J.C.; CARRIEDO, J.A.; SAN PRIMITIVO, F. Evaluation of rapid somatic cell counters under different analytical conditions in ovine milk. Jounal of Dairy Science, v.87, p.3623-3628, 2004.

GONZALO, C.; CARRIEDO, J.A.; BARO. J.A.; SAN PRIMITIVO, F. Factors affecting variation of test day milk yield, somatic cell count, fat, and protein in dairy sheep. Journal of Dairy Science, v.77, n.6, p.1537-1542, 1994.

GONZALO, C.; MARTINEZ, J.R.; CARRIEDO, J.A.; SAN PRIMITIVO, F. Fossomatic cell-counting on ewe milk: comparison with direct microscopy and study of variation factors. Journal of Dairy Science, v.86, p.138145,2003

HARMON, R. J.; EBERHART, D. E.; JASPER, B. E.; LANGLOIS, B. E.; WILSON, R. A. Microbiological procedures for the diagnosis of bovine udder 
infections. 3. ed. Arlington: VA, National Mastitis Council, 1990. 34 p.

JAEGGI, J.J.; GOVINDASAMY-LUCEY, S.; BERGER, Y.M.; JOHNSON, M.E.; MCKUSICK, B.C.; THOMAS, D.L.; WENDORF, W.L. Hard ewe's milk cheese manufactured from milk of three different groups of somatic cell count. Journal of Dairy Science, v.86, p.3082-3089, 2003.

JANDAL, J. M.; Comparative aspects of goat and sheep milk. Small Ruminant Research, v.22, p.177-185, 1996.

KIRK, J. H.; GLENN, J. S.; MAAS, J. P. Mastitis in a flock of milking sheep. Small Ruminant Research, v.22, p.187-191, 1996.

LAFI, S. Q.; AL-MAJALI, A. M.; ROUSAN, M. D.; ALAWNEH, J. M. Epidemiological studies of clinical and subclinical ovine mastitis in Awassi sheep in northern Jordan. Preventive Veterinary Medicine, v.33, p.171$181,1998$.

LEITNER, G.; CHAFFER, M.; CARASO, Y.; EZRA, E.; KABABEA, D.; WINKLER, M. GLICKMAN, A.; SARAN, A. Udder infection and milk somatic cell count, NAGase activity and milk compositions - fat, protein and lactose - in Israeli - Assaf and Awassi sheep. Small Ruminant Research, v.49, p.157-164, 2003.

MCCARTHY, F. D.; LINDSEY, J. B.; GORE, M. T.; NOTTER, D. R. Incidence and control of subclinical mastitis in intensively managed ewes. Journal of Animal Science, v.66, p.2715-2721, 2009.

MCDOUGALL, S.; MURDOUGH, P.; PANKEY, W.; DENANEY, C. BARLOW, J.; SCRUTON, D. Relationship among somatic cell count, California Masitis Test, impedance and bacteriological status of milk in goats and sheep in early lactation. Small Ruminant Research, v.40, p.245-254, 2001.

NUDDA, A.; FELIGINI, M.; BATTACONE, G.; MACCIOTTA, N.P.P.; PULINA, G. Effect of lactation stage, parity, $\beta$-lactoglobulin genotype and milk SCC on whey protein composition in Sarda dairy ewes. Italian Journal of Animal Science, v.2, p.29-39, 2003.

NUNES, G.R.; BLAGITZ, M.G.; FREITAS, C.B.; SOUZA, F.N.; RICCIARDI, M.; STRICAGNOLO, C.R.; SANCHES, B.G.S.; AZEDO, M.R.; SUCUPIRA, M.C.A.; DELLA LIBERA, A.M.M.P. Avaliação de indicadores inflamatórios no diagnóstico da mamite ovina. Arquivos do Instituto Biológico, v.75, n.3, p.271-278, 2008.

OLIVER, S.P.; LEWIS, M.J.; GILLESPIE, B.E.; DOWLEN, H.H.; JAENICKE, E.C.; ROBERTS, R.K. Microbiological Procedures for the Diagnosis of Bovine Udder Infection and Determination of Milk Quality. $4^{\text {th }}$ ed. Verona: National Mastitis Council, 2004. $47 \mathrm{p}$.
PAAPE, M.J.; POUTREL, B.; CONTRERAS, A.; MARCO, J.C.; CAPUCO, A.V. Milk somatic cells and lactation in small ruminants. Journal of Dairy Science, v.84, suppl.E, p.E237-E243, 2001.

PELLEGRINI, O.; REMEUF, F.; RIVEMALE, M.; BARILLET, F. Renneting properties of milk from individual ewes: influence of genetic and non-genetic variables, and relationship with physicochemical characterisitics. Journal of Dairy Research, v.64, p.355366, 1997.

PENGOV, A. The role of coagulase-negative Staphylococcus spp and associated somatic cell counts in the ovine mammary gland. Journal of Dairy Science, v.84, n.3, p.572-574, 2001.

PYÖRALLÄ, S. Indicators of inflammation in the diagnosis of mastites. Veterinary Research, v.34, p.565$578,2003$.

QUEIROZ, E.O.; SIQUEIRA, E.R.; NATEL, A.S.; NETO, A.P.; GOMES, H.F.B.; FERNANDES, S.; DE SOUZA, E.A. Efeito do período de ordenha na composição centesimal do leite de ovelhas da raça bergamásia mantidas a pasto. Revista Biodiversidade, v.8, n.1, p.48-54, 2009.

RAYNAL-LJUTOVAC, K.; PIRISI, A.; DE CRÉMOUX, R; GONZALO, C. Somatic cells of goat and sheep milk: analytical, sanitary, productive and technological aspects. Small Ruminant Research, v.68, p.126-144, 2007.

RIBEIRO, L.C.; PÉREZ, J.R.O.; CARVALHO, P.H.A.; SILVA, F.F.; MUNIZ, J.A.; OLIVEIRA JÚNIOR, G.M.; SOUZA, N.V. Produção, composição e rendimento em queijo do leite de ovelhas Santa Inês tratadas com ocitocina. Revista Brasileira de Zootecnia, v. 36, n. 2, p. 438-444, 2007.

SEVI, A.; ALBENZIO, M.; MARINO, R.; SANTILLO, A.; MUSCIO, A. Effects of lambing season and stage of lactation on ewe milk quality. Small Ruminant Research, v.51, p.251-259, 2004.

SEVI, A.; TAIBI, L.; ALBENZIO, M.; MUSCIO, A.; ANNIXXHIARICO, G. Effect of parity on milk yield, composition, somatic cell count, renneting parameters and bacteria counts of Comisana ewes. Small Ruminant Research, v.37, p.99-107, 2000.

SNOWDER, G.D.; GLIMP, H.A. Influence of breed, number of suckling lambs, and stage of lactation on ewe milk production and lamb growth under range conditions. Journal of Animal Science, v.69, p.923-930, 1991.

SOUZA, F.N.; BLAGITZ, M.G.; PENNA, C.F.A.M.; DELLA LIBERA, A.M.M.P.; HEINEMANN, M.B.; CERQUEIRA, M.M.O.P. Somatic cell count in small ruminants: friend or foe? Small Ruminant Research, v.107, p.65-75, 2012. 